\title{
A STUDY OF CO-INFECTION WITH NEISSERIA GONORRHOEAE AND CHLAMYDIA TRACHOMATIS IN MALE URETHRITIS
}

\author{
Subhash Reddy Dudhipala1, Prasad J. V. D. S2, Ratna Kishore L3, Venkata Ramana Godha ${ }^{4}$,Venkata Krishna Ananthula ${ }^{5}$, \\ Padmaja Pinjala6, Prasad K. $N^{7}$, Prasad Naik C. $M^{8}$
}

${ }^{1}$ Assistant Professor, Department of Dermatology, Osmania Medical College and Osmania General Hospital, Hyderabad, Telangana. ${ }^{2}$ Associate Professor, Department of Dermatology, Osmania Medical College and Osmania General Hospital, Hyderabad, Telangana. ${ }^{3}$ Civil Assistant Surgeon, Department of Dermatology, Osmania Medical College and Osmania General Hospital, Hyderabad, Telangana. ${ }^{4}$ Professor, Department of Dermatology, Osmania Medical College and Osmania General Hospital, Hyderabad, Telangana.

${ }^{5}$ Associate Professor, Department of Dermatology, Osmania Medical College and Osmania General Hospital, Hyderabad, Telangana. ${ }^{6}$ Associate Professor, Department of Dermatology, Osmania Medical College and Osmania General Hospital, Hyderabad, Telangana. ${ }^{7}$ Assistant Professor, Department of Dermatology, Osmania Medical College and Osmania General Hospital, Hyderabad, Telangana. ${ }^{8}$ Assistant Professor, Department of Dermatology, Osmania Medical College and Osmania General Hospital, Hyderabad, Telangana.

\begin{abstract}
BACKGROUND

Sexually Transmitted Infections (STI) remain a public health problem of major significance in most parts of the world. The incidence of acute STI is believed to be high in many countries and failure to diagnose (due to asymptomatic nature of STIs) and treating STI at an early stage may result in serious complications and sequelae including infertility, foetal wastage, ectopic pregnancy, anogenital cancer and premature death as well as neonatal and infant infections. The individual and national expenditure for STI care can be substantial.(1) STDs thus became first biological and medical problems, but also social and political health interventions fail to address the full complexity of these social diseases.(2) The recent emergence of HIV/AIDS has added new relevance to the history of STDs. In a remarkably short period of time, AIDS has become a dominant issue in both medical and social discussion of health.(3) The present study is undertaken to note the co-infection of Neisseria gonorrhoea and Chlamydia trachomatis in urethritis in male patients presenting with serous or mucopurulent, purulent discharge per urethra, clinically diagnosed as urethritis, attending the STD Department, Osmania General Hospital over a period of 12 months from January 2014 to December 2014.

The aim of this study was to study the co-existence of Neisseria gonorrhoea and Chlamydia trachomatis in the male urethritis. Settings and Design- The study was conducted at STD Clinic, Dept. of DVL, Osmania Medical College/Osmania General Hospital, Hyderabad and $1^{\text {st }}$ eligible 100 male patients with urethritis after passing through inclusion and exclusion criteria in the period of January 2014 to December 2014 were included in this study.
\end{abstract}

\section{MATERIALS AND METHODS}

It is a descriptive study in which consequent sampling method with zero intervals is followed. All eligible male patients complaining of urethral discharge were included in the study after taking the informed consent. A detailed sexual history and active urethral discharge on milking of urethra is collected for the study purpose.

\section{RESULTS}

The 100 male urethritis cases were studied in which N. Gonorrhoea is the cause in $74 \%$ of cases and Ch. Trachomatis is the cause in $14 \%$ of cases and in remaining $14 \%$ of cases the co-infection of N. Gonorrhoea and Ch. Trachomatis is the cause of urethritis.

\section{CONCLUSION}

While treating a case of male urethral discharge in the resource limited setting with poor laboratory support, a combination treatment effective against both N. Gonorrhoea and Ch. Trachomatis should be provided due to presence of co-infections.

\section{KEYWORDS}

Urethral Discharge, Serous Discharge, Mucopurulent Discharge, Neisseria Gonorrhoea, Chlamydia Trachomatis, Mixed Infections, Mixed STI, Chocolate Agar, Giemsa's Stain.

HOW TO CITE THIS ARTICLE: Dudhipala SR, Prasad JVDS, Kishore RL, et al. A study of co-infection with neisseria gonorrhoeae and chlamydia trachomatis in male urethritis. J. Evolution Med. Dent. Sci. 2017;6(49):3746-3750, DOI: $10.14260 /$ Jemds/2017/810

Financial or Other, Competing Interest: None.

Submission 13-05-2017, Peer Review 08-06-2017,

Acceptance 13-06-2017, Published 19-06-2017.

Corresponding Author:

Dr. Prasad J. V. D. S,

Associate Professor of STD/DVL,

Department of DVL (OP. No. 22),

$1^{\text {st }}$ Floor, OP Block, Osmania General Hospital,

Afzalgunj, Hyderabad-500013, Telangana.

E-mail:drjvdsp@gmail.com

DOI: $10.14260 /$ jemds $/ 2017 / 810$

\section{BACKGROUND}

Sexually Transmitted Diseases (STDs) are caused by a number of microorganisms; they produce a set pattern of signs and symptoms such as urethral discharge, acute swelling of the scrotum in men and enlarged glands in the groin.(1) Common STDs are gonorrhoea, syphilis, chancroid and non-gonococcal urethritis, hepatitis B infection, herpes simplex infection, human papilloma virus infection and AIDS. The incidence of Acute Sexually Transmitted Infections (STI) is believed to be high in many countries. 
It is a basic and tragic irony of human life that intimate physical relations entail the risk of infectious diseases. In the case of STDs, the stigma associated with sexual behaviour is often transferred to the diseases transmitted by that behaviour, often resulting in denial. Thus, social pathology is superimposed on top of the clinical pathology of the disease.

Urethritis is manifested as urethral discharge, dysuria or itching at the terminal part of the urethra. The characteristic physical finding is urethral discharge and the pathogenic confirmatory laboratory finding is an increased number of Polymorphonuclear Leukocytes (PMNL) on Gram stain of a urethral smear or in the sediment of the First Voided Urine (FVU).

Several organisms can cause infectious urethritis. The presence of Gram-Negative Intracellular Diplococci (GNID) on urethral smear is indicative of gonorrhoea infection, which is frequently accompanied by chlamydial infection. NonGonococcal Urethritis (NGU), which is diagnosed when examination findings or microscopy indicate inflammation without GNID is caused by C. trachomatis in $15 \%-40 \%$ of cases; however, prevalence varies by age group with a lower burden of disease occurring among older men.(4)

Increasingly, the attention is focused on underlying socioeconomic and cultural determinants of STDs in entire population, and on dynamic patterns of the spread of infection through sexual networks and through populations. Evaluation, effective diagnosis, treatment and counselling of the sex partners and breaking the chain of transmission is crucial to control STDs.

\section{Aim of Study}

To study the co-existence of Neisseria gonorrhoea and Chlamydia trachomatis in male urethritis.

\section{MATERIALS AND METHODS}

The present study is a descriptive study undertaken to note the Neisseria gonorrhoea and Chlamydia trachomatis in urethritis in male patients presenting with serous or mucopurulent or purulent discharge per urethra, clinically diagnosed as urethritis, attending the STD Department, Osmania General Hospital over a period of 12 months from January 2014 to December 2014.

The consecutive sampling methodology with zero intervals along with inclusion and exclusion criteria is followed; $1^{\text {st }}$ eligible 100 male patients in reproductive age group presenting with purulent or mucopurulent or serous discharge per urethra, clinically diagnosed as urethritis with informed consent were enrolled in the study starting from January 2014 to December 2014. The 100 sample size is selected for the convenience of laboratory examination and data calculation. A detailed personal and sexual history was taken and complete physical examination was carried out. A percentage calculation method is used.

\section{Inclusion Criteria}

Reproductive age group, history of sexual activity in the past 3 months, burning micturition and/or urethral discharge, willing for part of the study.

\section{Exclusion Criteria}

Patients not willing for the part of study, beyond the sexual active age group and no history of sexual activity in the past 3 months.
The smears of urethral discharge and blood samples were taken for investigation. Urethral discharge in men was collected by passage of sterile platinum loop into the urethra under aseptic precautions.

\section{The Diagnosis of Neisseria Gonorrhoeae}

Gram's stain was performed on the collected urethral smears and examined for the evidence of Gram negative intracellular diplococci within the polymorphonuclear leukocytes.(5)

The collected urethral smear was cultured on chocolate agar medium for Neisseria gonorrhoea and confirmed by sugar fermentation tests. In all cases, VDRL and HIV testing was done.

\section{The Diagnosis of Chlamydia Trachomatis}

Purple coloured intracytoplasmic inclusions in epithelial cells were confirmative with Giemsa stain.

Chlamydia antigens were serologically detected using an immunochromatographic method in patient discharged through rapid KIT method.

Due to non-availability of McCoy cells, culture was not done. However, the confirmative test for Chlamydia was done by PCR on urine samples. A presumptive diagnosis for Chlamydia infection was done by screening Gram stain of the urethral smear for the presence of 5 or more PMN per high power (XI000) field.

The First-Catch Urine (FCU) of $30 \mathrm{~mL}$ was collected and sent to reference laboratory and PCR assay was done to detect the lower limit in the range of one to ten elementary bodies.

A wet mount examination was done in all the cases for Trichomonas vaginalis; $10 \% \mathrm{KOH}$ preparation was done for any evidence of candidiasis.

A complete urine examination for albumin, sugar, microscopy and culture and sensitivity was conducted.

\section{RESULTS}

\begin{tabular}{|c|c|c|c|c|}
\hline $\begin{array}{c}\text { Age Group } \\
\text { (Yrs) }\end{array}$ & N.G & C.T & Co-Inf & Total \\
\hline $15-24$ & 33 & 4 & 7 & 44 \\
\hline $25-34$ & 23 & 10 & 4 & 37 \\
\hline $35-44$ & 10 & 0 & 1 & 11 \\
\hline $45-54$ & 6 & 0 & 2 & 8 \\
\hline Total & $\mathbf{7 2}$ & $\mathbf{1 4}$ & $\mathbf{1 4}$ & $\mathbf{1 0 0}$ \\
\hline \multicolumn{5}{|c|}{ Table 1. Age Incidence } \\
\hline
\end{tabular}

The maximum number of Urethral discharges seen in sexually active age group between 15 and 44 is 94, accounting to $94 \%$, of which $44(46 \%)$ are seen in the early part of onset of sexual activity, i.e. 15 - 24 age group (the youngest is 18 years and oldest is 49 years). This may be due to inadequate sexual knowledge on STI/RTI causation, inability to have sexual control in the early years of onset of sexual journey.

\begin{tabular}{|c|c|c|c|c|}
\hline Literacy Status & NG & CT & Co-Inf & Total \\
\hline Illiterates & 19 & 2 & 7 & 28 \\
\hline Primary Education & 28 & 5 & 3 & 36 \\
\hline $\begin{array}{c}\text { Secondary } \\
\text { Education }\end{array}$ & 15 & 5 & 2 & 22 \\
\hline College Education & 10 & 2 & 2 & 14 \\
\hline \multicolumn{6}{|c|}{ Table 2. Literacy Status } \\
\hline \multicolumn{6}{|c|}{} \\
\hline \multicolumn{7}{|c|}{} \\
\hline
\end{tabular}


The prevalence of urethritis in $86 \%$ of men with education up to secondary school implies that Sexual and Reproductive Health (SRH) education needs to be incorporated in the secondary level. The literacy will provide the opportunity to get information on STI/RTI causation and it will bring the behaviour change of risk reduction.

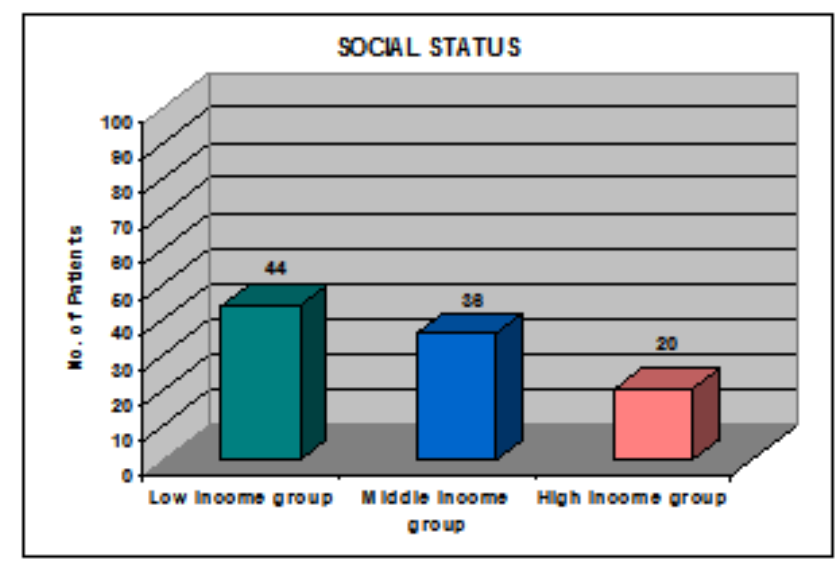

Figure 1. Social Status

The income of the individuals/family is one of the determinants of STI transmission and urethritis in our study is seen in $44 \%$ of low income group and $36 \%$ of middle income and only in $20 \%$ of high income group. An inverse relationship is seen between the income status and STI in our study group.

\begin{tabular}{|c|c|c|c|c|}
\hline Risk Factors & NG & CT & Co-Inf & Total \\
\hline Non use of condoms & 72 & 14 & 14 & 100 \\
\hline Lack of circumcision & 51 & 12 & 9 & 72 \\
\hline Alcoholism/smoking & 51 & 8 & 9 & 68 \\
\hline Multiple sex partners & 35 & 5 & 8 & 48 \\
\hline Single exposure & 21 & 3 & 0 & 24 \\
\hline \multicolumn{6}{|c|}{ Table 3. Risk Factors for Causation of Urethritis } \\
\hline
\end{tabular}

This study highlighted the risk of unprotected sex in transmission of urethritis, i.e. $100 \%$ followed by lack of circumcision in $72 \%$, influence of drugs and alcohol combined with sex in $68 \%$, multiple sexual exposures in $48 \%$ and least with the single sexual exposure in $24 \%$ in all 3 categories of urethritis patients.

Geographical Distribution: The urban population has increased chances to participate in casual sex, are more at risk of STI which is seen in 76 cases $(76 \%)$ compared with rural population of $24(24 \%)$ in our study.

Sexual Behaviour: The asymptomatic nature of gonococcal and chlamydia cervicitis is making the women not to perceive the presence of STI and it facilitating the sexual partners to have unprotected sex causing development of urethritis in 90 (90\%) of cases. However, the homosexuality contributed for $10(10 \%)$ of urethritis.

\begin{tabular}{|c|c|c|c|c|}
\hline Type and Cause & NG & CT & Co-Inf & Total \\
\hline Purulent & 46 & 7 & 10 & 63 \\
\hline Mucoid & 20 & 1 & 2 & 23 \\
\hline Mucopurulent & 6 & 6 & 2 & 14 \\
\hline Total & $\mathbf{7 2}$ & $\mathbf{1 4}$ & $\mathbf{1 4}$ & $\mathbf{1 0 0}$ \\
\hline \multicolumn{5}{|c|}{ Table 4. Nature of Discharge } \\
\hline
\end{tabular}

Urethritis manifested clinically as frank purulent urethral discharge in $63 \%$ of cases ( 46 by NG, 7 by CT and 10 by Coinfection) followed by Mucoid in 23\% (20 by NG, 1 by CT and 2 by Co-infection) and mixed type of mucopurulent type in $14 \%$ of cases ( 6 by NG, 6 by CT and 2 by Co-infection).

The Gonococcal urethritis (72 cases) manifested as purulent discharge in 46, as Mucoid discharge in 20 and Mucopurulent discharge in 6 cases. The Chlamydial urethritis (14 cases) was manifested as Purulent in 7, as Mucoid in 1 and Mucopurulent in 6 cases. However, in mixed urethritis (14 cases) it was manifested as purulent discharge in 10, mucoid and mucopurulent in 2 cases each.

\begin{tabular}{|c|c|c|c|c|}
\hline $\begin{array}{c}\text { Association with } \\
\text { other STDs }\end{array}$ & NG & CT & Co-Inf & Total \\
\hline Genital ulcers & 5 & 2 & 1 & 8 \\
\hline Genital warts & 3 & 0 & 1 & 4 \\
\hline Molluscum contagiosum & 4 & 0 & 0 & 4 \\
\hline Scabies and Pediculosis & 10 & 2 & 0 & 12 \\
\hline Other STDs & 7 & 0 & 1 & 8 \\
\hline Total & $\mathbf{2 9}$ & $\mathbf{4}$ & $\mathbf{3}$ & $\mathbf{3 6}$ \\
\hline Table 5. Association with other STDs \\
\hline
\end{tabular}

Mixed infections are common in STIs. In our study of urethritis there are $36 \%$ of mixed infections with other STIs, of which $8 \%$ is with Genital Ulcer Disease (GUD), $4 \%$ each with warts and molluscum, $12 \%$ with scabies and pediculosis and $8 \%$ with other STIs are seen.

Of the above associated STIs, VDRL is positive in 8 cases of Genital Ulcer Disease emphasising that Syphilis is the predominant cause. The Kumar BHA et al study at Bowring and LC Hospital, Bangalore showed the VDRL positivity in $17.5 \%$ of serum samples. ${ }^{(6)}$

\section{HIV Seropositivity}

Providers are in a particularly good position to diagnose persons during acute HIV infection, because such persons might present for assessment and treatment of a concomitantly acquired STD during this phase of the disease.(7) Depending on the frequency of coitus, men with average semen HIV-1 loads and without Sexually Transmitted Diseases (STDs) would be expected to infect $7 \%-24 \%$ of susceptible female sex partners during the first 2 months of infection. The predicted infection rate would be much higher when either partner has an STD.(8)

In the present study 20 patients (20\%) are found to be seropositives for HIV, of which 15 are of NG urethritis, 3 are of CT urethritis and 2 are having co-infection; 8 HIV seropositives are having other coexisting STIs.

A $20 \%$ seroprevalence of HIV in urethritis and presence of $36 \%$ of other coexisting STIs is an alarming sign, as $100 \%$ unprotected sex is contributing for transmission of both STIs and HIV.

\begin{tabular}{|c|c|c|}
\hline Result & Gram's Stain & Culture Results \\
\hline Positive & 86 & 86 \\
\hline Negative & 14 & 14 \\
\hline Total & $\mathbf{1 0 0}$ & $\mathbf{1 0 0}$ \\
\hline $\begin{array}{c}\text { Table 6. Interpretation of Gram's Stain and Culture } \\
\text { Results of Urethral Discharge (For Gonococci) }\end{array}$ \\
\hline
\end{tabular}


The sensitivity of Gram's stain is correlated with Gonococcal culture on chocolate agar and it is proved to be correlating in all 86 cases showing its sensitivity as 100\%.

\begin{tabular}{|c|c|c|c|}
\hline Result & $\begin{array}{c}\text { Giemsa's } \\
\text { Stain }\end{array}$ & Rapid Kit & $\begin{array}{c}\text { PCR } \\
\text { Assay }\end{array}$ \\
\hline Positive & 10 & 28 & 28 \\
\hline Negative & 90 & 72 & 72 \\
\hline Total & $\mathbf{1 0 0}$ & $\mathbf{1 0 0}$ & $\mathbf{1 0 0}$ \\
\hline
\end{tabular}

Table 7. Interpretation of Results for Chlamydia InfectionGiemsa's Stain, Immunochromatography (Rapid Kit) Method and PCR Assay

The sensitivity of Giemsa's stain (10 of 28) for chlamydia is $35 \%$ to Rapid Kit method and PCR Assay method in our study. However, the sensitivity of both Rapid Kit method and PCR assay are proved to be the same for Chlamydial identification in Urethral discharge.

\begin{tabular}{|c|c|}
\hline Cause of Urethritis & No. of Cases \\
\hline Gonococcal Urethritis & $\mathbf{7 2}$ \\
\hline Chlamydial Urethritis & 14 \\
\hline $\begin{array}{c}\text { Co-existence of gonococcal and } \\
\text { Chlamydia Urethritis }\end{array}$ & 14 \\
\hline Total & $\mathbf{1 0 0}$ \\
\hline $\begin{array}{c}\text { Table 8. Association of N. Gonorrhoea and } \\
\text { C. Trachomatis Infection in Urethritis }\end{array}$ \\
\hline
\end{tabular}

Out of the 100 cases of Male urethritis, in 72 cases Gonococcal infection and in 14 cases Chlamydial infection caused urethritis. However, in 14 cases there is co-infection of both N. Gonorrhoea and C. Trachomatis caused urethritis.

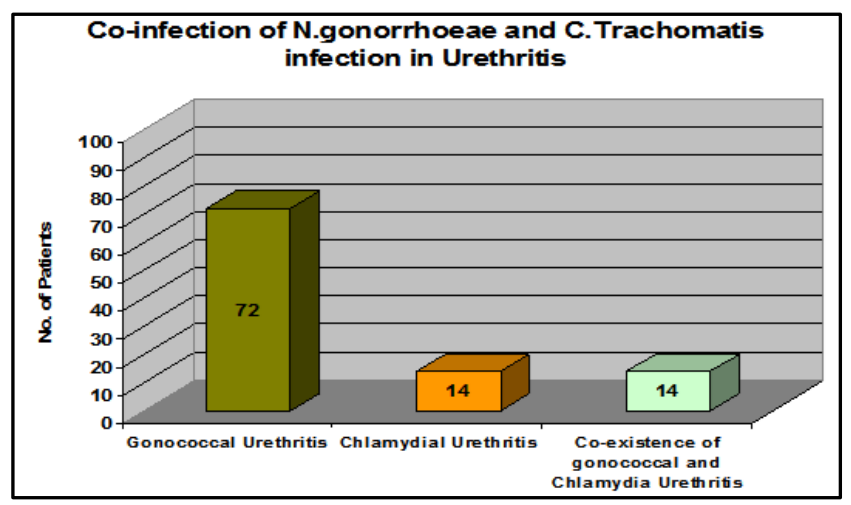

Figure 2. Association of NG and CT

\section{DISCUSSION}

The present study detected 14 cases of co-infection of Neisseria Gonorrhoea and Chlamydia Trachomatis among 100 patients presenting with urethritis attending the Department of DVL in Osmania General Hospital, Hyderabad over a period of 12 months. The overall prevalence of this coinfection was $14 \%$. According to a study conducted by Kumar BHA; Vijay D; Premalatha KG et al at Victoria Hospital, Bangalore, the prevalence of co-infection of Neisseria Gonorrhoea and Chlamydia Trachomatis was $12.5 \%$ in the year $2000,(6)$ whereas our study showed $14 \%$ which is approximately in concordance with the above study.

\begin{tabular}{|c|c|c|}
\hline Urethritis & $\begin{array}{c}\text { Study by } \\
\text { Bowring } \\
\text { et al }\end{array}$ & $\begin{array}{c}\text { Present Study at } \\
\text { Osmania General } \\
\text { Hospital }\end{array}$ \\
\hline Neisseria gonorrhoeae & $50 \%$ & $72 \%$ \\
\hline Chlamydia trachomatis & $12.5 \%$ & $14 \%$ \\
\hline $\begin{array}{c}\text { Co-infection of Neisseria } \\
\text { gonorrhoeae and } \\
\text { Chlamydia trachomatis }\end{array}$ & $12.5 \%$ & $14 \%$ \\
\hline
\end{tabular}

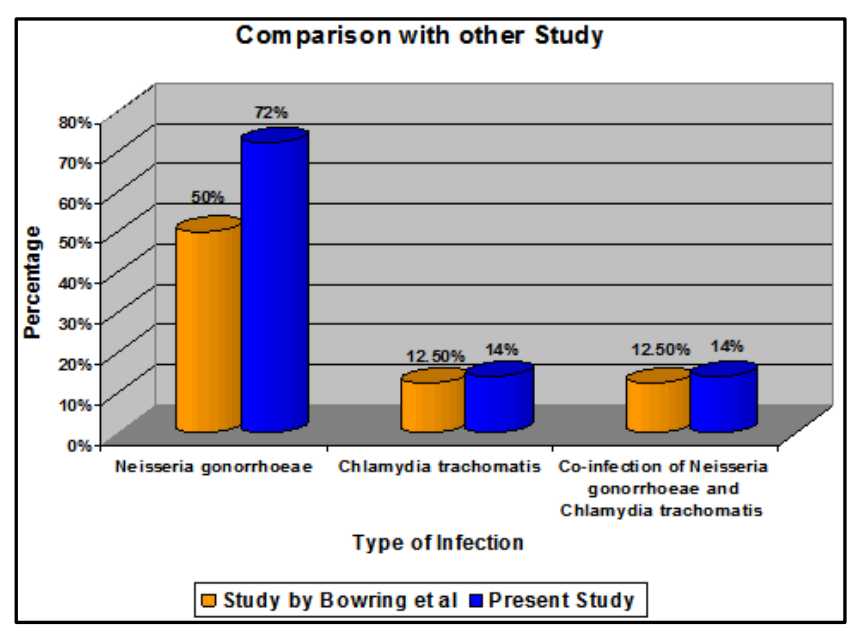

Figure 3. Comparison of Two Studies

The ramified statistics of the above table shows Neisseria gonorrhoea continues to be the major cause of urethritis, which is in accordance with our study.

The prevalence of urethritis is found to be more among the age group of 15 - 34 years, which constitute $82 \%$ of the infection (sexually active age group). Only $6 \%$ of infection was found in the age group of 45 - 54 years.

Significant association of urethritis was found in unmarried people accounting for $68 \%$ and married people accounted for $32 \%$ of the infection. Significant association of the infection was found with illiteracy and low socioeconomic status.

A wide range of risk factors played a cardinal role in the causation of urethritis in our study; $48 \%$ of them had multiple sex partners, while $24 \%$ had problem with a single exposure. Most of them were having casual sex partners. Alcoholism with or without smoking was found in $68 \%$ of the study group, which indicate increased incidence of STDs under the influence of alcohol. Unprotected sexual behaviour, alcohol and any substance use is a potential risk factor for the transmission of HIV and other Sexually Transmitted Infections (STI); $72 \%$ of people were uncircumcised which denotes a higher prevalence of the disease in them when compared to circumcision. All the patients in the study participated in unprotected sexual encounters making not using the condoms accounting for $100 \%$ of the problem.

The study being conducted at a cosmopolitan centre, wherein most of the patients in study group hailed from urban areas accounting for $76 \%$ of the problem, while $24 \%$ were from rural background. Rapid industrialisation, urbanisation and poverty resulting in urban migration accounted for higher number of cases from urban background. None had the history of neither blood transfusion nor intravenous drug uses. 
Taking the sexual behaviours into consideration, the urethritis was predominantly seen in persons with Heterosexual behaviours accounting for $84 \%$ of the total study. Homosexuality accounted for $10 \%$ of the cases and bisexuality was observed in $6 \%$ of the study group. Regarding the nature of discharge $23 \%$ presented with mucoid discharge, $63 \%$ with purulent discharge and $14 \%$ with mucopurulent discharge. It is showing that purulent discharge is the most common manifestation, both in Gonococcal and Chlamydial urethritis.

VDRL reactivity was observed in $8 \%$ of the cases of Genital Ulcers correlating with various stages of early acquired syphilis in the form of Genital Ulcer Disease.

A $20 \%$ of HIV sero-positivity was recorded in our study, which adds to the evidence of four-fold risk of HIV in association with urethral discharge.

The results of Giemsa's Stain for chlamydial inclusion bodies were found positive in 10 cases of the study group accounting for $10 \%$ of the infection, while remaining 90 smears were negative for inclusion bodies of the Chlamydia trachomatis, thus indicating a low sensitivity of the urethral samples by Giemsa's stain.

In the interpretation of urinary analysis of the specimens referred to reference laboratories assayed by PCR and Rapid Kit method for chlamydia trachomatis, positivity was found in 28 of the 100 cases, screening accounting for $28 \%$ of the total chlamydial cases. The performance of PCR in the diagnosis of chlamydial infection, especially in urine samples has become a Gold standard investigation. Its sensitivity when performed on First Catch Urine (FCU) has been between $89 \%$ and $100 \%$.

Other studies also showed the co-existence of Neisseria Gonorrhoea and Chlamydia Trachomatis infection such as Creighton S et al (18.8\%), Koneman et al (20\%), Lyss SB et al (20\% and $19 \%)$ and Nsuami $M$ et al $(11.1 \%$ and $42.7 \%)$.

\begin{tabular}{|c|c|}
\hline Study Group & Percentage of Co-Infection \\
\hline Creighton $\mathrm{S}^{(9)}$ & $18.8 \%$ \\
\hline Koneman et al $(10)$ & $20 \%$ \\
\hline Lyss SB(11) & $20 \%$ and $19 \%$ \\
\hline Nsuami M(12) & $11.1 \%$ and $42.7 \%$ \\
\hline \multicolumn{2}{|c|}{ Table 9. Comparative Studies of Co-Infection } \\
\hline
\end{tabular}

\section{CONCLUSION}

In the present study of 100 male urethritis cases $\mathrm{N}$. Gonorrhoea caused urethritis in 72 (72\%) cases, C. Trachomatis caused urethritis in $14(14 \%)$ cases and the coinfection of Neisseria gonorrhoea and Chlamydia Trachomatis causing male urethritis is seen in $14(14 \%)$ of the cases.

The various risk factors that are associated with the subjects in our study: unprotected sex with casual partners $(100 \%)$, lack of circumcision (72\%), alcoholism and smoking (68\%), multiple sexual exposures (48\%), single sexual exposure $(28 \%)$, presence of coexisting other STDs $(8 \%)$, living at far off places from the family for employment and homosexual behaviour.

The HIV sero-prevalence of $20 \%$ in male urethritis in our study is high and alarming when viewed against the state prevalence. Neisseria gonorrhoea continues to be the major cause of urethritis in India, whereas Chlamydia trachomatis is the major cause of urethritis in developed countries.
The strategies for detection and screening have been difficult, so that identification of the infected people with or without symptoms has been incomplete. Hence, the use of combinations of diagnostic kits for detection and control of the disease are recommended.

The frequent presence of chlamydia among patients at STD clinics who received treatment for gonorrhoea including sex partners of gonorrhoea-infected patients, supports continuing current recommendations for co-treatment.(12)

The syndromic approach is recommended for the control of N. Gonorrhoea and Chlamydia Trachomatis infection in all male urethritis cases due to its high co-existence.(13)

\section{REFERENCES}

[1] Guidelines for the management of sexually transmitted infections 2001. WHO/HIV_AIDS/2001.01 WHO/ RHR/01.10/http://www.who.int/hiv/ hiv_aids_2001_01.pdf.

[2] Rottingen JA, Cameron DW, Garnett GP. A systematic review of the epidemiologic interactions between classic sexually transmitted diseases and HIV: how much really is known? Sex Transm Dis 2001;28(10):579-97.

[3] Kremer M. Integrating behavioral choice into epidemiological models of the AIDS epidemic. National Bureau of Economic Research, Inc 1996.

[4] Bradshaw CS, Tabrizi SN, Read TR, et al. Etiologies of nongonococcal urethritis: bacteria, viruses, and the association with orogenital exposure. J Infect Dis 2006;193(3):336-45.

[5] Lai-King NG, Martin IE. The laboratory diagnosis of neisseria gonorrhoeae. Can J Infect Dis Med Microbiol 2005;16(1):15-25.

[6] Kumar BHA, Vijay D, Premalatha KG. Co-infection of neisseria gonorrhoeae \& chlamydia trachomatis in urethritis. Indian Journal of Sexually Transmitted Diseases 2001;22(1):24-6.

[7] www.cdc.gov/std/treatment/2010/hiv.htm.

[8] Pilcher CD, Tien HC, Eron JJ, et al. Brief but efficient: acute HIV infection and the sexual transmission of HIV. J Infect Dis 2004;189(10):1785-92.

[9] Creighton S, Tenant-Flowers M, Taylor CB, et al. Coinfection with gonorrhoea and chlamydia: how much is there and what does it mean? Int J STD AIDS 2003;14(2):109-13.

[10] Koneman. Seth barkely - diagnostic tests for sexually transmitted diseases. A Challenge Lancet 1994;343:685-6.

[11] Lyss SB, Kamb ML, Peterman TA, et al. Chlamydia trachomatis among patients infected with and treated for neisseria gonorrhoeae in sexually transmitted disease clinics in the United States. Ann Intern Med 2003;139(3):178-85.

[12] Nsuami M, Cammarata CL, Brooks BN, et al. Chlamydia and gonorrhea co-occurrence in a high school population. Sex Transm Dis 2004;31(7):424-7.

[13] http://naco.gov.in/sites/default/files/National\%20R TI\%20STI\%20technical\%20guidelines\%20Sep2014_1 .pdf Page 21-23. 